\title{
REESTRUTURAÇÃO URBANA NO BAIRRO DAS QUINTAS, NATAL-RN: A PERDA DO LUGAR
}

\author{
E. V. C. ARRUDA e M. L. M. GALVÃO* \\ Instituto Federal de Educação, Ciência e Tecnologia do Rio Grande do Norte - Campus Natal-Central \\ luiza.galvao@ifrn.edu.br
}

Artigo submetido em dezembro/2014 e aceito em dezembro/2014

DOI: 10.15628/geoconexoes.2015.2618

\section{RESUMO}

Partindo dos impactos produzidos pelas prováveis desapropriações dos moradores do entorno do viaduto da Urbana no bairro das Quintas - Natal, Rio Grande do Norte, o presente estudo pretende averiguar os possíveis efeitos socioespaciais ocasionados por essa obra de reestruturação urbana, que se dará em virtude da escolha de Natal como sede dos jogos da Copa do Mundo FIFA 2014. Para isso utilizou-se como recurso metodológico uma pesquisa bibliográfica que abarcou discussões sobre os conceitos de lugar, identidade e urbanismo. Como fomentadores desse arcabouço destacam-se autores como Carlos (2007), Tuan (1980) e Lefebvre (1991). Além disso, uma pesquisa documental foi realizada para consolidar informações acerca das desapropriações que seriam produzidas por meio da efetivação do projeto de mobilidade urbana. Nessa perspectiva, a fim de analisar os possíveis impactos quanto à perda do lugar e identidade dos moradores foi aplicada entrevistas abertas que retrataram a experiência e expectativa da população local sobre o projeto. Por fim, destaca-se a análise dos impactos, assim como, sua discussão.

PALAVRAS-CHAVE: Mobilidade. Desapropriação. Perda do Lugar.

\section{URBAN RESTRUCTURING IN QUINTAS NEIGHBORHOOD, NATAL-RN: A LOSSPLACE OF LOSS}

\begin{abstract}
Based on the likely impacts produced by the expropriation of residents surrounding the viaduct of the Urbana in the neighborhood Quintas - Natal, Rio Grande d Norte, this study intends to investigate the possible effects Sociogeographic caused by this work of urban restructuring, which will occur as a result of Natal's choice to host the matches of FIFA World Cup2014.For that we used as a methodology that included a literature discussions on the concepts of place, identity and urbanism. As developers of this framework stand out
\end{abstract}

authors like Carlos(2007), Tuan(1980) and Lefebvre(1991). In addition, documentary research was undertaken to consolidate information about the expropriations that would be produced by effecting design of urban mobility. From this perspective, in order to examine the possible impacts as loss of place and identity of the residents was applied open interviews that portray the experience and expectations of local people about the project. Finally, there is the analysis of impacts, as well as its discussion.

KEYWORDS: Mobility. Expropiation. Loss of Place. 


\section{INTRODUÇÃO}

A escolha de Natal, capital do Rio Grande do Norte, como uma das cidades sede para os jogos de Copa do Mundo da Fédération Internationale de Football Association (FIFA) 2014 em 31 de maio de 2009, implicava no atendimento a uma série de requisitos celebrados na Matriz de Responsabilidade proposta aos governos Federal, Estadual e Municipal a fim de viabilizar as ações necessárias à realização do referido Megaevento.

Diante disso, todos os interesses do Poder Público se curvaram aos objetivos propostos pelas necessidades do evento privado e de grande porte que se avizinha.

Assim, de acordo com a Matriz de Responsabilidade (2010, p. 2, grifo do autor) couberam as gestões estaduais e municipais entre outras coisas:

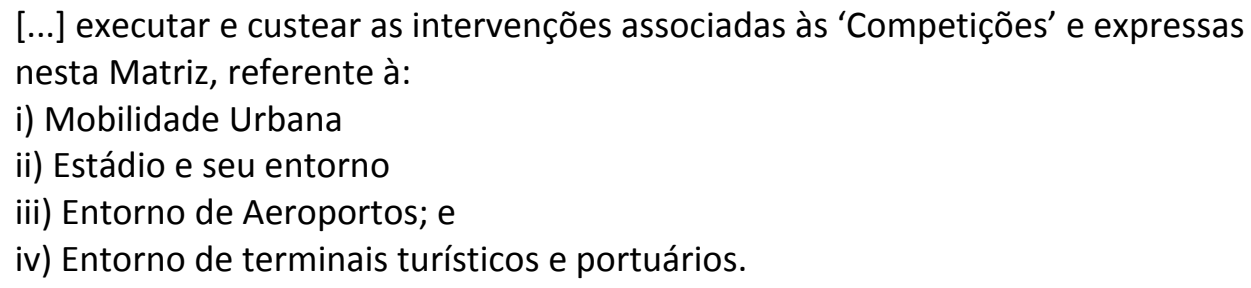

Nesse contexto, a Prefeitura Municipal do Natal ficou incumbida de executar obras e intervenções que possibilitem a melhora da mobilidade urbana da cidade nos trajetos que ligam o aeroporto ao estádio, assim como, o entorno dos mesmos. Planeja-se a execução de um projeto de mobilidade urbana que visa à construção de um corredor estrutural que cortará a zona oeste da cidade, ligando o Aeroporto de São Gonçalo do Amarante, a Rodoviária, a e Arena das Dunas assim como será visto a frente.

Nesse contexto, o bairro das Quintas constitui um território inserido no referido projeto. 0 corredor estrutural oeste possui em sua composição um complexo viário denominado "Complexo Viário da Urbana", localizado no citado bairro, mais precisamente na área conhecida como "corrente".

Segundo a Prefeitura Municipal, a intervenção em discussão "pretende ampliar um viaduto melhorando a estrutura do viaduto existente" (NATAL, 2012, p. 5), e justifica-se "pelo legado de infraestrutura e serviços" (NATAL, 2012, p. 7) que a cidade vai dispor no pós Copa. Porém, para construção do citado complexo, se faz necessário às desapropriações de 37 imóveis entre residências comerciam e mistos (residencial e comercial), que de acordo com o Poder Público Municipal são inevitáveis. Assim, no intuído de averiguar os impactos e sucessivamente as consequências que as desapropriações ditas inevitáveis causarão aos possíveis atingidos, é que se formulou a problemática norteadora desse trabalho.

Buscou-se ao longo da pesquisa verificar qual o sentimento da população com relação à mudança que ocorrerá com a perda do lugar e a desfragmentação do território em virtude das desapropriações. Observou-se que as prováveis desapropriações têm gerado medo e insegurança nos moradores, que constituíram naquele lugar suas relações socioeconômicas, políticas e culturais, e que possivelmente deixarão de fazer parte daquele território, cedendo lugar a reestruturação urbana em questão. 
Dessa forma, este trabalho justifica-se pela relevância científico/teórica por possibilitar um estudo sobre a relação Lugar/Identidade em função das desapropriações que ali serão realizadas. Além da nossa inserção no contexto, que também é um ponto importante, uma vez que, compartilhamos o medo e a insegurança gerada pela provável perda do lugar de identidade, laços afetivos e relações construídas ao longo dos anos, tidas como ponto de referência.

\section{TEORIA E PROCESSO PARA DESAPROPRIAÇÕES: UMA RELAÇÃO CONFLITUOSA}

O estudo em tela tem como revisão bibliográfica os conceitos de urbanismo, território, lugar e identidade, que aqui serão desenvolvidos com intenção de fundamentar a discussão. (continuar o raciocínio) Inicia-se essa revisão a partir do conceito de urbanismo utilizado por Lefebvre (1991, p. 24, grifo do autor) no qual, ele discute o urbanismo dito científico, e tido como o urbanismo dos administradores (no caso em tela, do poder executivo), "que acompanha as formas deliberadas do racionalismo operatório, tende a negligenciar o 'fator humano'."

Essa negligência do "fator humano", desse "fator social" se personifica no estudo em tela com a desconsideração das relações sociais já consolidadas no território do bairro das Quintas, onde as desapropriações estão para ocorrer, em virtude da referida reestruturação urbana. A obra de reestruturação urbana proposta, faz "uma análise fragmentária da realidade considera." (LEFEBVRE, 1991, p. 24), tendo em vista atender requisitos de uma Matriz Responsabilidade cujo objetivo é: "viabilizar a execução de ações governamentais necessárias à realização das 'competições'" (2010, p. 2, grifo do autor) na cidade.

Assim, o escopo da obra se resume em garantir a mobilidade entre o aeroporto de São Gonçalo do Amarante e a Arena das Dunas, assim como apresentado no próximo capitulo. Dessa forma, a obra em discussão tem por finalidade promover uma reestruturação urbana não com interesse de projetar uma cidade melhor, "mas de definir 'imagens-objetivo' a serem atingidas" (COSTA; MENDONÇA, 2008, p. 52, grifo do autor). Imagens que façam com que a cidade passe a operar de maneira rentável para o capital nacional e estrangeiro investidos no megaevento Copa do Mundo FIFA 2014, preocupando-se minimamente com a real necessidade urbana da cidade.

\section{BAIRRO DAS QUINTAS: UM BREVE RESGATE GEO-HISTÓRICO}

Localizado na zona administrativa Oeste da cidade do Natal, capital do Rio Grande do Norte, o bairro das Quintas mantém os mesmos limites desde 1994 ${ }^{1}$, são eles: ao Norte Rio Potengi, ao Sul Dix-Sept Rosado/Bom Pastor, ao Leste Alecrim, e ao Oeste Nordeste.

A localidade que viria ser o bairro das Quintas originou-se em 1717, quando a área que o compõem, até então devoluta, foi doado pelo senado da câmara ${ }^{2}$ ao Sr. Antônio Gama Luna, que estabeleceu ali uma "quinta", o que segundo Cascudo (1999, p. 255), "eram casas de campo com terreno de plantio, o mesmo que granja."

\footnotetext{
${ }^{1}$ Conforme Lei no $251 / 47$ alterada pela lei № 4.330, de 05 de abril de 1993, que redefine os limites do bairro, passando a vigorar a partir de sua publicação no DOE em 07/09/1994.

${ }^{2}$ Era um órgão de poder legislativo, executivo e judiciário responsável pela administração das vilas e cidades, atuando como representante dos interesses da população.
} 
Ainda segundo Cascudo (1999) em 1731 a área passou a ser conhecida como Quinta Velha, devido a outras quintas que ali existiam. Esse fato deu origem a atual nomenclatura do bairro.

Por mais de dois séculos, o recorte espacial que corresponde ao atual bairro foi constituído por "uma imensa área rural com povoamento rarefeito" (SOUZA, 2008, p. 707). Assim, antes de possuir configuração de bairro e ter sua oficialização ${ }^{3}$ promulgada em 1947, na administração ${ }^{4}$ do então prefeito Sylvio Pedroza, as Quintas era uma área rural constituída por sítios e granjas.

No entanto, o crescimento da cidade do Natal para além dos limites campo-cidade ocorrido na década de 1940, desencadeou uma transformação socioespacial na referida área. Souza (2008, p. 708), ratifica que "as correntes migratórias procedentes do interior para a capital do estado durante a II Guerra Mundial adensou o povoamento das Quintas". Desse modo, a ampliação dos limites da cidade, em função das citadas correntes migratórias, foi o fator impulsionador na ocupação e expansão do bairro.

Inserida nessa caracterização, a área em destaque no mapa abaixo, denominada "Corrente", corresponde ao objeto de estudo da pesquisa em tela. Segundo dados da Secretária de Meio Ambiente e Urbanismo (SEMURB, 2009), essa denominação se deu em virtude da área ter sido considera, por mais de 20 anos, o limite da cidade ao norte (caminho do município de Natal ao município de Macaíba), onde existia um posto de fiscalização estadual no qual era obrigatória a parada de veículos para fins de inspeção.

Diante disso, o proclamo dessas possíveis desapropriações, ditas necessárias, para a execução do projeto provocou nos moradores e comerciantes daquela área, medo e insegurança frente às incertezas do futuro, tendo em vista que, possivelmente perderão o lugar no qual estabeleceram suas dinâmicas socioeconômicas, políticas e culturais construídas a partir de relações mantidas naquele território.

Outro fator que também corrobora para o aumento das incertezas diz respeito à omissão do Poder Público Municipal em prestar esclarecimentos sobre como se darão os processos desapropriatórios, com visto, após quase dois anos, ainda não se tem conhecimento de informações básicas como, o número efetivo de imóveis atingidos e/ou a serem desapropriados e os prazos para entrega dos mesmos. Além disso, até o referido momento a prefeitura não apresentou nenhuma proposta concreta de intervenção que vise mitigar os impactos que as desapropriações causarão aos atingidos e/ou aos moradores desse bairro.

\subsection{A REESTRUTURAÇÃO URBANÍSTICA}

O projeto de mobilidade urbana, apresentado e defendido pelo Poder Público Municipal, estabelece a criação de um corredor estrutural ligando o Aeroporto de São Gonçalo de Amarante, o terminal Rodoviário, à Arena das Dunas e a rede hoteleira da capital, situada na Via Costeira, assim como pode ser conferido na imagem. A obra em si, está dividida em dois lotes: o primeiro lote (eliminar esta palavra) consiste na construção de um corredor estrutural que possuirá 4.780,00 metros de extensão, iniciando-se na cabeceira da Ponte Presidente Costa e Silva, popularmente conhecida como ponte de Igapó, localizado na Zona Norte de Natal, passando pelos bairros das Quintas no qual, haverá intervenções na Avenida Felizardo Moura, e no /Viaduto da

\footnotetext{
${ }^{3}$ Conforme lei № 251, de 30 de Setembro de 1947.

${ }^{4}$ Administração municipal de 1946 a 1951.
} 
Urbana, consecutivamente, seguindo pelo Bom Pastor, também situado na zona oeste, onde as intervenções se darão basicamente, na Avenida Industrial João Francisco da Motta, até o encontro com a Avenida Capitão-Mor Gouveia (SEMURB, 2012).

As intervenções propostas para essa primeira etapa incidem na correção geométrica das avenidas Felizardo Firmino Moura e Industrial João Francisco da Motta, assim como a construção de um complexo viário no bairro das Quintas, que se localizará na área conhecida como "Corrente". As obras do segundo lote correspondem à continuação do corredor estrutural pela Avenida Capitão-Mor Gouveia até o encontro com a Avenida Prudente de Morais no bairro de Lagoa Nova, na zona administrativa sul de Natal.

Nessa etapa, as intervenções consistem na correção geométrica de todo a extensão a Avenida Capitão-Mor Gouveia, que corresponde a 3,8 km, assim como, a construção de pontilhão sobre a linha férrea seguindo o mesmo padrão da avenida, além de, um viaduto de livre circulação, no entroncamento da referida avenida com a Avenida Industrial João Francisco da Motta. Além disso, todo o trajeto da obra contará, com três faixas para cada sentido de tráfego, sendo uma para uso exclusivo de transporte de massa, além de canteiros centrais, ciclovias e áreas de passeio para pedestres.

Ademais, todo o percurso será dotado de mobiliário urbano acessível à pessoa com deficiência, assim como ordena a lei. Para a execução do referido projeto, o Poder Público Municipal alegou a necessidade de promover algumas desapropriações, no ínterim de quase dois anos, o número de imóveis passiveis a esses processo sofreu diversas alterações, inicialmente estavam previstas 1.000 (mil) desapropriações, entretanto, a partir de uma primeira revisão do projeto esse número passou para 600 (seiscentos) imóveis, diminuindo assim, 400 expropriações, a partir de uma segunda revisão do projeto procedida pela SEMURB, o número de desapropriações variou entre 429 e 449, ficando efetivamente em 449 imóveis (SEMUB, 2013).

Apesar da diminuição, o número de desapropriações ainda assim é elevado, além disso, há todo um descaso com os possíveis atingidos, tendo em vista que mesmo com um número oficial de desapropriações, a sociedade civil desconhece quem realmente será afetado, isso, faz com que as expropriações sejam o ponto crucial de todo o processo.

Como dito, entre as obras previstas para o primeiro lote do projeto em discussão, encontrase o Complexo Viário Urbana. A construção do referido complexo engloba a edificação de um viaduto, a reestruturação do viaduto existente e dos acessos e alças da via, com pista dupla, além das ciclovias, passeio para pedestre e mobiliário urbano acessível à pessoa com deficiência.

Ademais, todo o percurso será dotado de mobiliário urbano acessível à pessoa com deficiência, assim como ordena a lei. Para a execução do referido projeto, o Poder Público Municipal alegou a necessidade de promover algumas desapropriações, no ínterim de quase dois anos, o número de imóveis passiveis a esses processo sofreu diversas alterações, inicialmente estavam previstas 1.000 (mil) desapropriações, entretanto, a partir de uma primeira revisão do projeto esse número passou para 600 (seiscentos) imóveis, diminuindo assim, 400 expropriações, a partir de uma segunda revisão do projeto procedida pela SEMURB o número de desapropriações variou entre 429 e 449, ficando efetivamente em 449 imóveis (SEMURB, 2013).

Apesar da diminuição, o número de desapropriações ainda assim é elevado, além disso, há todo um descaso com os possíveis atingidos, tendo em vista que mesmo com um número oficial 
de desapropriações, a sociedade civil desconhece quem realmente será afetado, isso, faz com que as expropriações sejam o ponto crucial de todo o processo. Como dito, entre as obras previstas para o primeiro lote do projeto em discussão, encontra-se o Complexo Viário Urbano. A construção do referido complexo engloba a edificação de um viaduto, a reestruturação do viaduto existente e dos acessos e alças da via, com pista dupla, além das ciclovias, passeio para pedestre e mobiliário urbano acessível à pessoa com deficiência.

\section{ENTRE A (IN)CERTEZA DA DESAPROPRIAÇÃO E A (IN)CERTEZA DO FUTURO: A PERDA DO LUGAR}

Historicamente, em nosso país, os processos desapropriatórios se dão de maneira conturbada e em sua maioria, negligenciam o fator humano e o fator social das áreas atingidas, assim, como pode ser constatado no caso em tela.

No lugar em debate ( $\mathrm{Na}$ área em questão), o número de imóveis passiveis a desapropriação corresponde a 37, divididos em residenciais, mistos e comerciais, ocupados em sua maioria por seus proprietários originais que, segundo pesquisas in loco, residem há no mínimo 20 anos naquela localidade. Inclua-se dentro dessa configuração a autora desse trabalho, haja vista que reside na área passível de sofrer as desapropriações e compartilha da angústia de perder os vínculos criados ao longo dos anos com aquele lugar, onde se construiu todas as dinâmicas sócio-políticas, econômicas e culturais, definindo-o assim como "identitário, relacional e histórico." (AUGÉ, 1994, p. 73).

Identitário, pois, todos que ali habitam reconhecem naquele lugar e no cotidiano a sua identidade territorial. Ali construíram relações sociais mais finas (estreitas), as de vizinhança, além do encontro diário com pessoas, com as quais compartilham problemas e conquistas. Quanto ao histórico, registraram em suas memórias, suas lembranças e imagens da vida diretamente ligadas ao que é vivido naquele lugar.

Para Carlos (2007 p. 18) "São as relações que criam o sentido dos lugares" e assim, como dito anteriormente, o sentido daquele lugar existe porque existem relações de prática social construídas ali. Quem lá há anos reside, sofre com a possível perda do que foi construído, das relações ali cultivadas e colhidas.

\section{CONSIDERAÇÕES FINAIS}

Uma vez não construída a obra de mobilidade e não ocorrendo as desapropriações tornouse um tanto subjetivo falar dos efetivos impactos provocados na área escolhida para discussão neste trabalho. Nesse sentido a relevância da discussão se deve ao favorecimento que a ciência geográfica permite discorrer sobre os prováveis impactos causados aos moradores da "localidade Corrente" com a provável perda do lugar.

O trabalho permitiu concluir que os interesses do Poder Público Municipal estão voltados à viabilização das intervenções necessárias a realização dos jogos da Copa do Mundo FIFA 2014 em Natal, capital do Rio Grande do Norte, deixando em segundo plano os prováveis expropriados e a própria cidade como um todo, visto que as intervenções urbanas a serem realizadas servirão apenas como "gargalos" a fim de satisfazer as exigências do comitê da copa e não dos moradores 
da cidade como um todo. A Gestão Municipal edificou um muro entre os praticantes do espaço e o projeto proposto, os que ali residem, sequer foram informados oficialmente a respeito de como se dará os processos desapropriatórios.

Ante ao exposto, os que se encontram inseridos no espaço que dará lugar a obra de mobilidade convivem com uma situação de incerteza e insegurança com relação ao futuro que se difunde a cada nova informação veiculada pela mídia e confirmada na pesquisa empírica, quando se constatou como se expressam os impactos adversos promovidos pela possível desapropriação, a exemplo da nossa convivência diária com incerteza e insegurança, tanto como pesquisadora, como provável atingida.

Analisar e discutir uma situação na qual nos encontramos inseridos foi trabalhoso, pois separar o emocional do racional exigiu imparcialidade, principalmente no decorrer das entrevistas, pois compartilhamos do medo, da insegurança e da indignação narrada, não só de "perder" o bem material, mas, de ser expropriado do lugar onde nos conhecemos e nos reconhecemos.

Termos nossos direitos de cidadãos violados, quando da não participação popular na constituição dos projetos, nós os praticantes do espaço, nos sentimos como marginalizados do processo de escolha e decisão. Além disso, ainda convivemos com o impasse referente ao inicio das obras e consecutivamente as efetivas desapropriações.

Partilhar do sentimento da possível perda do lugar, saber exatamente o que está sendo narrado pelo entrevistado é algo indescritível, o envolvimento sentimental e político, tendo em vista a nossa participação direta na luta pela defesa dos direitos estatuídos pela lei com relação à construção de uma cidade justa e acessível a todos, garantiu que construíssemos uma discussão critica a respeito da constituição do projeto e das suas possíveis consequências.

Ademais, a construção desse trabalho nos aproximou das discussões com a Gestão Pública Municipal a respeito das possibilidades de revisão do projeto e consequentemente das desapropriações, garantindo assim, que defendêssemos os nossos direitos de forma concisa e fundamentada. Diante disso, a nossa pretensão é não concluir a discussão, uma vez que a obra de mobilidade ainda está pra acontecer, e em qualquer tempo que ela aconteça sempre haverá impactos causadores de sofrimento. Assim, esperamos com este trabalho ter contribuído com a ciência geográfica e fomentado o interesse de novos estudos sobre esse tema.

\section{REFERENCIAS}

1. ASSOCIAÇÃO POTIGUAR DOS ATINGIDOS PELA COPA 2014 (Brasil). Estatuto: APAC 2014. Natal, 2011.

2. AUGÉ, Marc. Não Lugares: introdução a uma antropologia da supermodernidade. Campinas, SP: Papirus,1994.

3. BRASIL. Decreto-lei no 3.365, de 21 de junho de 1941, Dispõe sobre desapropriações por utilidade pública. Presidência da República, Casa Civil, DF, 21 de Junho 1941.

4. BRASIL. Lei $\mathbf{n} \mathbf{0} \mathbf{1 0 . 2 5 7}$, de $\mathbf{1 0}$ de julho de 2001, Estatuto das Cidades. Regulamenta os arts. 182 e 183 da Constituição Federal, estabelece diretrizes gerais da política urbana e dá outras providências. Presidência da República, Casa Civil, DF, 10 de Julho de 2001.

5. BRASIL. Lei no 10.098, de 19 de dezembro de 2000, Estabelece normas gerais e critérios 
básicos para a promoção da acessibilidade das pessoas portadoras de deficiência ou com mobilidade reduzida, e dá outras providências. Presidência da República, Casa Civil, DF, 19 de Dezembro de 2000.

6. BRASIL. Lei no $\mathbf{4 . 1 3 2}$, de 10 de setembro de 1962, Define os casos de desapropriação por interesse social e dispõe sobre sua aplicação. Presidência da República, Casa Civil, DF, 10 de Setembro de 1962.

7. BRASIL. Ministério das Cidades. Presidência da República. PAC - Copa Natal: Eixos de Intervenção. Disponível em: <http://www.cidades.gov.br/index.php/progsemob/948-paccopa-natal>. Acesso em: 12 set. 2012.

8. CASCUDO, L. C. História da cidade de Natal. 3. ed. Natal: IHG, 1999.

9. CASTELLS, Manuel. O Poder da Identidade: A era da Informação: Economia, Sociedade e Cultura. 3. ed. São Paulo-SP: Paz e Terra, 2002.

10. CARLOS, Ana Fani Alessandri. O Lugar no/do Mundo. São Paulo, SP:

11. FELCH, 2007.

12. COMITÊS POPULARES DA COPA (Brasil) (Org.).Mega Eventos e Violação de Direitos Humanos no Brasil: Sumário Executivo. 2. ed. Rio de Janeiro, 2012.

13. FONTANELLA, Bruno José Barcellos; RICAS, Janete; TURATO, Egberto Ribeiro. Amostragem por saturação em pesquisas qualitativas em saúde: contribuições teóricas. Caderno de Saúde Pública, Rio de Janeiro- RJ, p. 17-27. 01 jan. 2008. Disponível em: <http://www.scielo.br/scielo.php?pid=s0102-311×2008000100003\&script=sci_arttext>. Acesso em: 20 dez. 2012.

14. HAESBAERT, Rogério. Desterritorialização: entre as Redes e os Aglomerados de Exclusão in: CASTRO, Iná Elias de. CORRÊA, Roberto Lobato. GOMES, Paulo Cesar da Costa (Org). Geografia: Conceitos e Temas. 7 ed. Rio de Janeiro: Bertrand, 2005.

15. LEVEBVRE, Henri. Direito a Cidade. São Paulo: Morais, c1991.

16. MONTE-MÓR, Roberto Luís de Melo (Org.). Do urbanismo à política urbana: notas sobre a experiência brasileira. In: COSTA, Geraldo Magela; MENDONÇA, Jupira Gomes. Planejamento urbano no Brasil: trajetória, avanços e perspectivas. Belo Horizonte: C/arte, 2008. Cap. 1, p. 31-65.

17. NATAL, Lei complementar no 082, de 21 de junho de 2007. Dispõe sobre o Plano Diretor de Natal e dá outras providências. Diário Oficial do Município, Edição Especial, Poder Executivo, Natal, RN, 21 de Junho de 2007, p.1.

18. NATAL. Secretária Municipal Obras Públicas e Infraestrutura - SEMOPI. Prefeitura Municipal do Natal. Relatório de Controle Ambiental - RCA: Para Licenciamento as Obras do Complexo Viário. Natal, 2012.

19. PORTAL DA COPA 2014 (Org.). Imagens do Complexo Viário da Urbana. Disponível em: $<$ http://www.portal2014.org.br/galeria-de-

fotos/319/IMAGENS+DO+COMPLEXO+VIARIO+DA+URBANA+EM+NATAL.html acessado em>. Acesso em: 25 mar. 2012.

20. PORTAL DA COPA 2014 (Org.). Matriz de Responsabilidades. Disponível em: <http:// www.copa2014.gov.br/pt-br/sobre-a-copa/matriz-de-responsabilidades.html acessado em>. 
Acesso em: 20 set. 2012.

21. PREFEITURA MUNICIPAL DO NATAL. Diário Oficial do Município. Publicação do Decreto de Desapropriação. № 9.649, de 15 de março de 2012. Disponível em: <http://www.natal.rn.gov.br/_anexos/publicacao/dom/dom_20120308.pdf>. Acesso em: 16 mar. 2012.

22. PREFEITURA MUNICIPAL DO NATAL. Diário Oficial do Município. Publicação do Decreto de Desapropriação. №. 9.635, de 07 de março de 2012. Disponível em: <http://www.natal.rn.gov.br/_anexos/publicacao/dom/dom_20120308.pdf>. Acesso em: 08 mar. 2012.

23. PREFEITURA MUNICIPAL DO NATAL. Semurb (Org.). Meu Bairro, Minha Cidade. Disponível em: $<$ http://www.natal.rn.gov.br/semurb/paginas/File/bairros/natal_meu_bairro_minha_ cidade.pdf $>$. Acesso em: 16 nov. 2011.

24. SAQUET, Marcos Aurelio. Por uma Abordagem Territorial. In: SAQUET, Marcos Aurelio. SPOSITO, Eliseu Savério (Org). Territórios e Territorialidades: teorias, processos e conflitos. São Paulo: Expressão Popular, 2009, p. 73-94.

25. SOUZA, Itamar de. Nova história de Natal: 40 anos de pesquisa. 2. ed. Natal: Departamento Estadual de Imprensa, 2008.

26. SOUZA, Marcelo José Lopes de. O Território: sobre Espaço e Poder, Autonomia e Desenvolvimento in: CASTRO, Iná Elias de. CORRÊA, Roberto Lobato. GOMES, Paulo Cesar da Costa (Org). Geografia: Conceitos e Temas. 7 ed. Rio de Janeiro: Bertrand, 2005.

27. TRIBUNA DO NORTE: Há 428 imóveis no meio do caminho. Natal, 11 dez. 2011. Disponível em: <http://tribunadonorte.com.br/noticia/ha-428-imoveis-no-meio-do-caminho/205643>. Acesso em: 21 mar. 2012.

28. TUAN, Yu-fu. Topofilia: Um Estudo da Percepção, Atitudes e Valores do Meio Ambiente. São Paulo-SP: DIFEL, 1980. 